\title{
A prospective study of the factors affecting access to equitable surgical care in the Southern Province of Rwanda
}

\author{
Ahmed Kiswezi ${ }^{1}$, Robert Munyaneza', David Karenzi ${ }^{2}$, Sylvie Inyange ${ }^{2}$ \\ 1. University Teaching Hospital of Butare (CHUB), Butare, Rwanda \\ 2. University of Rwanda, Kigali, Rwanda \\ Correspondence: Dr Ahmed Kiswezi (ahmedkiswezi@yahoo.com)
}

C) 2018 A. Kiswezi et al. This open access article is licensed under a Creative Commons Attribution 4.0 International License (http://creativecommons.org/licenses/by/4.0/), which permits unrestricted use, distribution, and reproduction in any medium, provided you give appropriate credit to the original author(s) and the source, provide a link to the Creative Commons license, and indicate if changes were made.

East Cent Afr J Surg. 2018 Aug;23(2):55-58 https://dx.doi.org/10.4314/ecajs.v23i2.1

\begin{abstract}
Background

Access to equitable surgical care significantly reduces morbidity and mortality from traumatic injuries, abdominal, extra-abdominal, acquired and congenital conditions. In Rwanda, like many other developing countries, there are is a wide range of factors affecting access to surgical care across the different levels of health care delivery. The main objective of this study was to document the factors affecting access to surgical care in the Southern Province of Rwanda.

\section{Methods}

This prospective observational study randomly selected 5 of the 11 district hospitals in the province. The other health unit included was the regional referral hospital for the province, Butare (CHUB). The variables tested included surgical capacity, timeliness, safety, and affordability, for all the included health units in the province. The lists of elective surgical patients, compared with the lists of operated patients over a period of six months, were used to indicate the performance and outputs to surgical access for the various health units in this study. In addition, 5 patient interviews were conducted at each health unit, from patients who were randomly selected, from both the surgical outpatients and the surgical wards. They were questioned regarding their views to surgical care access. Percentages were used to indicate the extent of the challenges to surgical access.
\end{abstract}

\section{Results}

The lack of adequate surgical staff was the commonest challenge to surgical access (75\% for the district hospitals, and $10 \%$ for the regional referral hospital) identified. At the regional referral hospital (CHUB), limited operating theatre space was a challenge in $50 \%$ of the cases. This was followed by the limited number of specialists and sub-specialties rated at 10\%, and limited anesthetic plus ICU facilities rated at 10\%. The other challenge was the issue of affordability for the consumables required, rated at 10\% The average surgical output and the pending (representing unmet need), calculated from the elective waiting lists for a period of 6 months, indicated that the number of operated patients were rated at $75 \%$, and an unmet need of surgical access of $25 \%$ for CHUB; while for the district hospitals it was $63 \%$ with an unmet need of $37 \%$.The patients' views also pointed at challenges of limited surgical services at the district hospital (70\%), and affordability (30\%).

\section{Conclusions}

Access to surgical care in the Southern Province of Rwanda was affected by the limited number of specialists and doctors with the minimum skills to carry out non-specialized operations at the district hospitals, the limited operating theatre facilities, limited sub-specialist services, and specialized investigations.

Keywords: surgical care, access, challenges, capacity, safety, affordability, timing

\section{Introduction}

Surgical care is increasingly recognized globally as a great contributor to public health, as it significantly reduces morbidity and mortality from traumatic injuries, maternal, ab- dominal and extra-abdominal conditions, acquired and congenital conditions. In developing or low income countries, the estimates of inadequate access to surgical care are very high compared to those in developed countries. This corresponds to the low patient / doctor ratio in the low and 
Table 1: Elective patients on waiting lists for the different hospitals: mean monthly values

\begin{tabular}{|c|c|c|c|c|c|c|}
\hline $\begin{array}{l}\text { Operation } \\
\text { category }\end{array}$ & $\begin{array}{l}\text { CHUB } \\
\text { Regional } \\
\text { Hospital }\end{array}$ & $\begin{array}{c}\text { Kabgayi } \\
\text { District } \\
\text { Hospital }\end{array}$ & $\begin{array}{c}\text { Kabutare } \\
\text { District } \\
\text { Hospital }\end{array}$ & $\begin{array}{c}\text { Kigeme } \\
\text { District } \\
\text { Hospital }\end{array}$ & $\begin{array}{c}\text { Kinazi } \\
\text { District } \\
\text { Hospital }\end{array}$ & $\begin{array}{c}\text { Gakoma } \\
\text { District } \\
\text { Hospital }\end{array}$ \\
\hline General & 82 & 30 & 10 & 6 & 4 & 2 \\
\hline Orthopaedic & 36 & - & - & - & - & - \\
\hline Paediatric & 10 & - & - & - & - & - \\
\hline Urology & 6 & - & - & - & - & - \\
\hline $\begin{array}{l}\text { Obstetrics and } \\
\text { gynaecology }\end{array}$ & 30 & 20 & 12 & 10 & 12 & 5 \\
\hline Other & 5 & - & - & - & - & - \\
\hline Monthly total & 169 & 50 & 22 & 16 & 16 & 7 \\
\hline $\begin{array}{l}\text { 6-month } \\
\text { mean }\end{array}$ & 1014 & 300 & 132 & 96 & 96 & 42 \\
\hline
\end{tabular}

Table 2: Percentage of surgical output versus surgical care demand calculated from the elective patients alone (6 months cumulative figures)

\begin{tabular}{|c|c|c|c|c|c|c|}
\hline $\begin{array}{c}\text { Access } \\
\text { challenge }\end{array}$ & $\begin{array}{l}\text { CHUB } \\
\text { Regional } \\
\text { Hospital }\end{array}$ & $\begin{array}{c}\text { Kabgayi } \\
\text { District } \\
\text { Hospital }\end{array}$ & $\begin{array}{l}\text { Kabutare } \\
\text { District } \\
\text { Hospital }\end{array}$ & $\begin{array}{c}\text { Kigeme } \\
\text { District } \\
\text { Hospital }\end{array}$ & $\begin{array}{c}\text { Kinazi } \\
\text { District } \\
\text { Hospital }\end{array}$ & $\begin{array}{c}\text { Gakoma } \\
\text { District } \\
\text { Hospital }\end{array}$ \\
\hline Waiting list & 1014 & 300 & 132 & 96 & 96 & 66 \\
\hline Surgical output & 966 & 212 & 86 & 72 & 60 & 34 \\
\hline $\begin{array}{l}\text { No \& specialty } \\
\text { of Drs } \\
\text { operating }\end{array}$ & $\begin{array}{c}7 \text { surg } 5 \\
\text { gyn }\end{array}$ & $\begin{array}{l}1 \text { Family } \\
\text { Dr, MO }\end{array}$ & $2 \mathrm{MO}$ & $\begin{array}{c}1 \text { visits } 1 \\
\text { MO }\end{array}$ & $1 \mathrm{MO}$ & $2 \mathrm{MO}$ \\
\hline$\%$ output & 75 & 70 & 65 & 75 & 62 & 52 \\
\hline $\begin{array}{l}\text { \% unmet } \\
\text { demand }\end{array}$ & 25 & 30 & 35 & 25 & 38 & 48 \\
\hline
\end{tabular}

medium income countries (WHO recommendation: 1doctor/ 1000 people; Rwanda: 1 doctor/ 12,000 people- RMDPC report 2016)

Worldwide, lack of access to equitable surgical care is a significant challenge to the health care systems. Most of the countries with high percentages of inadequate access to equitable surgical care are in sub-Saharan Africa and Asia. ${ }^{1}$

Global studies on surgical access, including those by United Nations, have often analyzed the challenges to surgical access by breaking them into timeliness or how soon the surgical services are offered; capacity to offer the needed surgical services; safety of the surgical services; and affordability by the patients'. WHO considers access to safe caesarean sections as critical and cost-effective in reducing both neonatal and maternal mortality and long-term disability such as obstetric fistulae. In the 49 countries identified by WHO in 2008 with inadequate provision of caesarean sections, it was estimated that obstructed labor and subsequent maternal mortality cost 1.1 million disability adjusted life-years per year globally. ${ }^{1}$ In communities where district hospitals have the capacity to offer essential surgical care, given that they are more accessible by many rural communities, early surgical interventions often allow for the treatment of surgical conditions before they result in complications requiring specialized and/ or expensive treatment, or mortality. ${ }^{1,2}$

Whereas the health care system of Rwanda has registered great milestones including community based health insurance (mutuelle de santé), performance based financing, and some of its hospitals undergoing international accreditation, inequitable access to surgical care is still high. The challenges responsible for this have not been fully analyzed and documented. At the referral hospital of Butare (CHUB), there are often overwhelmingly increasing numbers of patients on the waiting lists anticipating surgical care. For many of them surgery may be done after several weeks or months of waiting patiently due to the high numbers versus limited theatre and bed facilities. It is not clear whether this is due to increasing demand or inadequate output, or both. Throughout 
Table 3: Surgical Access Challenges Versus their effects (summarized)

\begin{tabular}{|c|c|c|}
\hline $\begin{array}{c}\text { Challenge at Regional referral } \\
\text { (CHUB) }\end{array}$ & Challenge at District Hospitals & Effects \\
\hline Limited operating space $\&$ beds & $\begin{array}{l}\text { Limited surgical and anesthetic } \\
\text { service }\end{array}$ & Prolonged waiting time (electives) \\
\hline Sub-specialty surgical services & 966 & 212 \\
\hline Special investigations & $\begin{array}{l}\text { Limited surgical and anesthetic } \\
\text { service }\end{array}$ & Referral to other hospitals \\
\hline $\begin{array}{l}\text { Prolonged appointments; long } \\
\text { distances from home; affordability }\end{array}$ & Limited surgical services & $\begin{array}{l}\text { Referral to other hospitals/ } \\
\text { Delayed surgical access }\end{array}$ \\
\hline
\end{tabular}

the East African region, research and evidence based information on this subject which may form a basis for action plans aiming at enhancing access to surgical care, is scanty or often lacking.

\section{Methods}

This prospective observational study sampled different levels of health care delivery in the southern province of Rwanda. The initial steps included piloting carried out at one district hospital. This provided us with the required evidence, the basis of which we used in the development of the questionnaire for this study. Five out of the 11 district hospitals were included in the study, selected by simple random sampling from all the 11 district hospitals in the province, by picking 5 out of 11 sealed envelopes, each containing a name of one district hospital. The regional Referral hospital in the province, Butare (CHUB) was also included. The variables tested included capacity, timeliness, safety, and affordability, for all the included health units in the province. Capacity was tested by assessing Operating theatre facilities, the operations, Anesthetic coverage, Intensive Care coverage, Nursing coverage and capacity to handle the sub-specialties. Safety was tested by assessing the effective use of the surgical safety check-list, infection control methods, and quality of clinical documentation. Timeliness was assessed by looking at the period of appointments and how long patients stayed on the elective booking lists. Affordability was tested by assessing the percentage of surgical patients who had an up-to-date insurance (mutuelle de santé), those who could afford the health-unit treatment costs versus those who could not. One Questionnaire was assigned to each health unit for data collection. The lists of elective surgical patients, compared with the lists of operated patients over the last six months were used to indicate the output and the reasons for the surgeries not done, in the various health units. Surgical service data was accessed to evaluate the lists of booked elective, and the operated patients. In addition, 5 patient interviews were conducted at each health unit, from patients who were randomly selected from both the surgical out-patients' clinics, and surgical wards, by picking one envelope containing "yes" or "no". They were questioned regarding their views to surgical care access and the barriers faced if any. Percentages were used to indicate the extent of the challenges to surgical ac- cess. This study was sanctioned by the Rwanda Surgical Society, and the Research and Ethics review Board, representing the Ministry of Health. At the Health unit, the authorities were approached for permission and informed consent, and determination of the respondent(s) to the questionnaire.

\section{Results}

Lack of the basic skills for the doctors to carry out the non-specialized operations was more significant at almost all the district hospitals in the study (75\%).

The district hospitals with doctors who have skills to carry out non-specialized surgical operations had high output and reduced un-met demand for surgical care. Example: Kabgayi, Kigeme.

\section{Discussion}

One of the main challenges to surgical access identified in this study was limited human resources for surgical services. With only 7 general surgeons, 1 orthopedic surgeon, 5 gynecologists, and 3 Ear Nose \&Throat surgeons to offer the needed surgical care in the province, and the majority of them in them working only at the regional referral hospital; it is clear that the human resource deficit is significant. Many of the cases that are operable at the district hospitals such as hernia, Hydrocele, emergency splenectomy, (usually referred to as non-specialist operations) are often referred due to lack of doctors with enough experience or exposure to be able to operate them at the District hospital. The study found out that among the included district hospitals in the region, it was only Kigeme hospital, with a visiting specialist surgeon, and Kabgayi hospital, with a specialist in Family practice carrying out operations, which were not referring such cases. In many LMICs, district hospitals have doctors who are able to handle common and uncomplicated emergency surgical cases. ${ }^{2,3}$

As a result of under-utilizing the district hospitals, as was indicated by this study, and the study by Ntakiyiruta, Wong and Rousseau et al. in Rwanda, ${ }^{6}$ the non specialist operations compete with the specialist operations at the referral hospital, thus overwhelming the waiting lists. Rwanda is not alone in this, as studies indicate that many countries including South Africa and Australia have a similar challenge. In an effort to avert the challenge in South Africa, it was proposed in 
their "White Paper" that District hospitals be strengthened to handle non specialist operations in order to increase access for specialist operations at the referral hospitals. ${ }^{2,3,6}$

The referrals from the regional referral hospital to other referral hospitals in Kigali City were often for specialized investigations such as CT-scan, MRI-scan, MRCP, or angiography; and for the sub-specialty surgical services such as urology, plastic, neuro-surgery or pediatric surgery, and chemotherapy. This challenge of travelling long distances for more specialized care is not unique to Rwanda, which happens to have a good distance to health unit (average $=5 \mathrm{~km}$, compared to the WHO recommendation of $3 \mathrm{~km}$ ). Studies suggest that many countries including Australia and New Zealand share the same challenge. ${ }^{3,4,7}$

The challenge of inadequate numbers of Anesthesia Officers and limited ICU facilities was real especially at the referral hospital. They were shared between emergency cases, gynecology \& obstetrics, elective surgery, and ENT. One group often had to be on hold if there was an obstetric emergency, given the limited numbers of anesthetic officers. This was part of the limited capacity that posed a big challenge for the province. The average number of patients requiring ICU at CHUB per week was 20, but with only 6 beds in the unit, the situation was so challenging. Studies suggest that a similar situation exists in other countries in the developing world. ${ }^{5}$

Even if most of the patients (90\%) in this region presented with community insurance, its processing was often delayed, taking several weeks. In addition, it did not cover $100 \%$ of the charges. Many patients were not able to pay the extra charges, or even pay for the theatre consumables in time. The situation was even worse if special investigations such as CT-scan or MRI were required. This was a challenge to both the patients and the surgeons. Additionally, there was the challenge of those who presented without insurance, yet their conditions required urgent care. Collective patients' views indicated that they were not satisfied with the limited surgical services at the district hospitals. This has some similarity to the South African situation. ${ }^{3,4}$

\section{Conclusions}

This study found out that there were multiple challenges to surgical access in the Southern Province of Rwanda. They include the limited number of specialists, and doctors with the minimum skills to carry out non-specialized operations at the district hospitals, the limited operating theatre facilities, limited number of sub-specialist services, the limited specialized investigations and often inaccessible cancer treatment. These accounted for about $90 \%$ of the challenges, while $10 \%$ of the challenges are related to affordability. The patients' opinions echoed similar challenges.

\section{Competing interests}

All authors declare that they have no competing interests related to this work.

\section{References}

1. Wong EG, Deckelbaum DL, RazekT. Global access to surgical care: moving forward. Lancet Glob Health. 2015 Jun;3(6):e298-9. doi: 10.1016/S2214-109X(15)00004-2

2. Forrester JD, Forrester JA, Kamara TB, Groen RS, Shrestha S, Gupta S, et al. Self-reported determinants of access to surgical care in 3 developing countries. JAMA Surg. 2016 Mar;151(3):257-63. doi: 10.1001/jamasurg.2015.3431.

3. Rayne S, Burger S, Straten SV, Biccard B, Phaahla MJ, Smith M. Setting the research and implementation agenda for equitable access to surgical care in South Africa. BMJ Glob Health. 2017 Jun 14;2(2):e000170. doi: 10.1136/ bmigh-2016-000170. eCollection 2017.
4. World Health Organization (WHO) Strengthening emergency and essential surgical care and anaesthesia as a component of universal health coverage: report by the secretariat [Internet]. Geneva: WHO; c2014. Available from: http://apps.who.int/iris/ handle/10665/251803.

5. Samad L, labal M, Tariq A, Shahzad W, Khan AJ. Equitable access to comprehensive surgical care: the potential of indigenous private philanthropy in low-income settings. World J Surg. 2015 Jan;39(1):218. doi: 10.1007/s00268-014-2852-0.
6 Ntakiyiruta G, Wong EG., Rousseau MC Ruhungande L, Kushner AL, Liberman AS, et al. Trauma care and referral patterns in Rwanda: implications for trauma system development. Can J Surg. 2016 Feb;59(1):35-41. doi: 10.1503/cjs.008115.

7. Ssebuufu R, Pawelzik V, Megentta A, Benimana O, Mazimpaka D, Ndoli J, et al. A case study: applying quality improvement methods to reduce preoperative length of stay in a resourceconstrained setting in Rwanda. J Hosp Adm. 2016;5(1):41-7. doi: 10.5430/jha. v5n1p41. 